\title{
Effect of Injection Pressures on Emissions of Direct Injection Diesel Engine By Using CFD Simulation
}

\author{
C.Anuradha ${ }^{1}$, T. Anand Kumar ${ }^{2}$, Dr. M .Lakshmi Kantha Reddy ${ }^{3}$, \\ Dr.G.Prasanthi ${ }^{4}$ \\ ${ }^{1}$ P.G. Research Scholar, Adv.I.C.Engines, Dept of Mech. Engg., JNTUA College of Engg, Ananthapuramu- \\ 515001,India \\ ${ }^{2}$ Principal Application Engineer,CD-adapco,Banglore-506066,Karnataka, India. \\ ${ }^{3}$ Professor \& Principal, Mother Theresa Institute of Engineering \& Technology, Palamaneru, Chittor-517408, \\ A.P.India \\ ${ }^{4}$ Professor, Dept of Mechanical Engineering, JNTUA College of Engineering, Ananthapuramu -515001, Andhra \\ Pradesh, India
}

\begin{abstract}
Internal combustion engines, now a days is the best available reliable source of power for all domestic, large scale industrial and transportation applications. The major issue arises at the efficiency of these engines. The major pollutants are Un Burned Hydro Carbons (UBHC), and Oxides of Nitrogen (Nox).These are formed due to incomplete combustion of the fuel in combustion chamber of diesel engine. One of the important factors which influence the performance and emission of diesel engine is fuel injection pressure. An experimental study was performed on a light duty direct injection diesel engine at $150 \mathrm{bar}, 200$ bar and $250 \mathrm{bar}$ injection pressure to study its effect on performance and emission These emissions can be controlled by different techniques like EGR, changing the injection pressure of fuel into the combustion chamber etc., It is a well known fact that as the injection pressure of fuel increases, the mass flow rate of fuel will vary for proper mixing of fuel and air in the combustion chamber. In the present work, it is proposed to investigate the effect of variations in injection pressure on emissions and for this STAR-CD will be used as a tool. To aid the setup of these calculations, visualization and interpretation of results, $C D$ - Adapco has developed a pre and postprocessor environment, es-ice which is a special tool in STAR-CD solver which will be used for this analysis.

The performance and emission characteristics were presented graphically and concluded that they were found better at the fuel injection pressure 200 bar for the light duty engine.
\end{abstract}

Keywords: Sector mesh, Injection pressure, Diesel Engine, Emissions (Soot \& Nox), CFD Simulation.

\section{Introduction}

The diesel engine is a type of internal combustion engine more specifically, it is a compression ignition engine, in which the fuel ignited solely by the high temperature created by compression of the air-fuel mixture. The engine operates using the diesel cycle. The diesel engine is more efficient than the petrol engine, since the spark-ignition engine consumes more fuel than the compression-ignition engine. In present diesel engines, fuel injection systems have designed to obtain higher injection pressure. So, it is aimed to decrease the exhaust emissions by increasing efficiency of diesel engines. When fuel injection pressure is low, fuel particle diameters will enlarge and ignition delay period during the combustion will increase. When injection pressure increased of fuel particle diameters will become small. Since formation of mixing of fuel to air becomes better during ignition period, engine performance will be increase. If injection pressure is too higher, ignition delay period becomes shorter. Possibilities of homogeneous mixing decrease and combustion efficiency falls down The fuel injection system in a direct injection diesel engine is to achieve a high degree of atomization in order to enable sufficient evaporation in a very short time and to achieve sufficient spray penetration in order to utilize the full air charge. The fuel injection system must be able to meter the desired amount of fuel, depending on ngine speed and load, and to inject that fuel at the correct time and with the desired rate. By affecting the air/fuel mixture, you can achieve better and more efficient combustion, which leads to more power. The bowls have a variety of different shapes; some are also designed to optimize fuel economy. With direct injection becoming the hottest new technology for gasoline engines, expect uniquely bowled pistons to become more and more popular. In high-speed direct-injection Diesel engines, the flow conditions inside the cylinder at the end of the compression stroke, near top dead center (TDC), are critical. for the combustion process. These are determined by the air flowing into the cylinder through the intake valves during the induction process and by its evolution during the compression stroke. The mixing of fuel and air becomes better during ignition delay period which causes low smoke level and $\mathrm{CO}$ emission. But, if the injection pressure is too high ignition delay become shorter. So, possibilities of homogeneous mixing decrease and combustion efficiency falls down. Therefore, 
smoke is formed at exhaust of engine. For this work hemispherical bowl shape is taken into account, which are shown in Fig1 This piston bowl shape is prepared from the standard CAD design-package.

\section{Computational Procedure}

CFD simulation subtle elements with creating the sector grid using es-ICE(Experts systems in Internal Combustion Engine). A 450 Sector grid is made taking the favorable position symmetric way of the dish shape. This is appeared in Fig.1

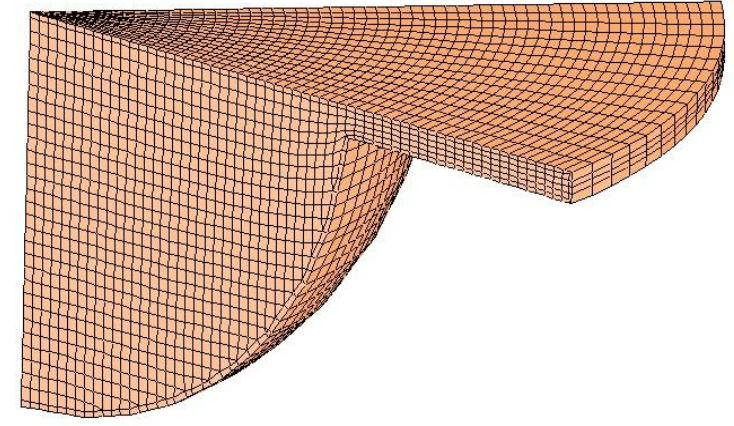

Fig.1.45 sector mesh at TDC

Subsequent to making the part work in es-ICE, this sector grid is utilized as a part of STARCONTROL for applying the initial conditions, boundary conditions like beginning temperature, initial pressure, and cylinder crown temperature and so on. At that point this sector grid is utilized as a part of PRO-STAR for applying the fuel properties and injection parameters like injection temperature, nozzle hole diameter etc. After completion of PRO-STAR, simulation is begins in SOLVER. Then after results are gotten from post processing in es-ICE. Injection droplets in cylinder bowl of direct injection diesel engine at different injection pressures at 2 deg before TDC are shown in Fig2,Fig3 and Fig4.

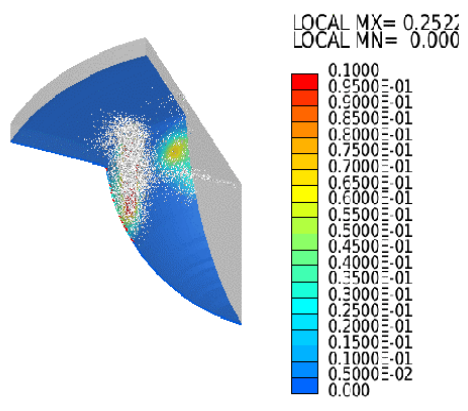

Fig2.At Injection Pressure 150 bar

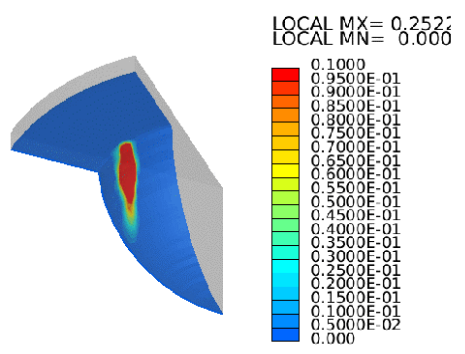

Fig3.At Injection Pressure 200 bar 


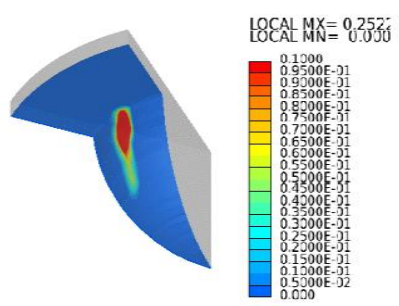

Fig4.At Injection Pressure 250 bar

\section{Engine Parameters \& Details}

Engine Specifications:

The engine parameters for which the piston bowl mesh is generated is given Table.1.

Table.1

\begin{tabular}{|c|l|}
\hline Particulates & Specifications \\
\hline Engine & KIRLOSKAR ENGINE \\
\hline Type & Water-cooled \\
\hline Ignition system & Compression ignition \\
\hline Cylinder arrangement & Vertical \\
\hline Maximum speed & $1500 \mathrm{rpm}$ \\
\hline Number of Cylinder & 1 \\
\hline Bore & $85 \mathrm{~mm}$ \\
\hline Stroke & $110 \mathrm{~mm}$ \\
\hline Compression Ratio & $17.5: 1$ \\
\hline Maximum HP & $5 \mathrm{HP}$ \\
\hline Fuel & HSD \\
\hline
\end{tabular}

\section{Equations}

In CFD analysis, for change the Injection pressure of diesel engine it has to be change the mass flow rate of the fuel. Here calculating the mass flow rate of fuel at different injection pressures

$V\left(\frac{m}{s}\right)=\frac{\sqrt{2 \times(\text { Injection Pressure }- \text { Cylinder pressure })}}{\text { Density of fluid }}$

$\mathrm{M}(\mathrm{kg} / \mathrm{s})=$ Density $\times$ Area of Nozzle $\times$ Velocity of Fluid

At injection Pressure 150 bar

$\mathrm{v}(\mathrm{m} / \mathrm{s})=\sqrt{\frac{2 \times(150-50) \times 10^{5}}{832}}=155.04 \mathrm{~m} / \mathrm{s}$

$\mathrm{m}(\mathrm{kg} / \mathrm{s})=832 \times 1.256 \times 10^{-7} \times 155.04=0.0162 \mathrm{~kg} / \mathrm{s}$

At Injection Pressure 200 bar

$\mathrm{M}(\mathrm{kg} / \mathrm{s})=832 \times 1.256 \times 10^{-7} \times 189.88=0.0198 \mathrm{Kg} / \mathrm{s}$

$$
V\left(\frac{m}{s}\right)=\frac{\sqrt{2 \times(200-50) \times 10^{5}}}{832}=189.88 \mathrm{~m} / \mathrm{s}
$$

At Injection Pressure 250 bar

$\mathrm{M}(\mathrm{kg} / \mathrm{s})=832 \times 1.256 \times 10^{-7} \times 219.26=0.0229 \mathrm{Kg} / \mathrm{s}$

$$
V\left(\frac{m}{s}\right)=\frac{\sqrt{2 \times(250-50) \times 10^{5}}}{832}=219.26 \mathrm{~m} / \mathrm{s}
$$

Where,

$\mathrm{V}=$ Velocity of the fluid, $\mathrm{m} / \mathrm{sec}$.

$\mathrm{m}=$ mass flow rate of the fluid, $\mathrm{kg} / \mathrm{sec}$.

\section{Results And Discussions}

Cylinder pressure, Cylinder temperature, Apparent Heat release rate, NOx and soot emissions are obtained by CFD simulation for the same piston geometry which is used literature [1].Injection Pressures are varied from 150 bar to 250 bar.. The cylinder pressures increases till 736 deg CA due to diffusion combustion and thereafter decreases gradually. It is found that the peak pressure during the simulation reaches nearly 47 
bars at nearly $740{ }^{\circ} \mathrm{CA}$ for Injection Pressure 180 bar, At Injection Pressure 250 bar the cylinder pressure increases to 52.6 bars. The Cylinder temperature are also increases from $1080{ }^{0} \mathrm{~K}$ to $1300{ }^{0} \mathrm{~K}$ and also apparent heat release rate is increases from $18 \mathrm{~J} / \mathrm{deg}$ to $23.5 \mathrm{j} / \mathrm{deg}$ The variation of cylinder pressures ,Cylinder temperatures and Apparent heat release rate with respect to crank angle at different Injection Pressure are shown in Fig 5,Fig6 and Fig 7

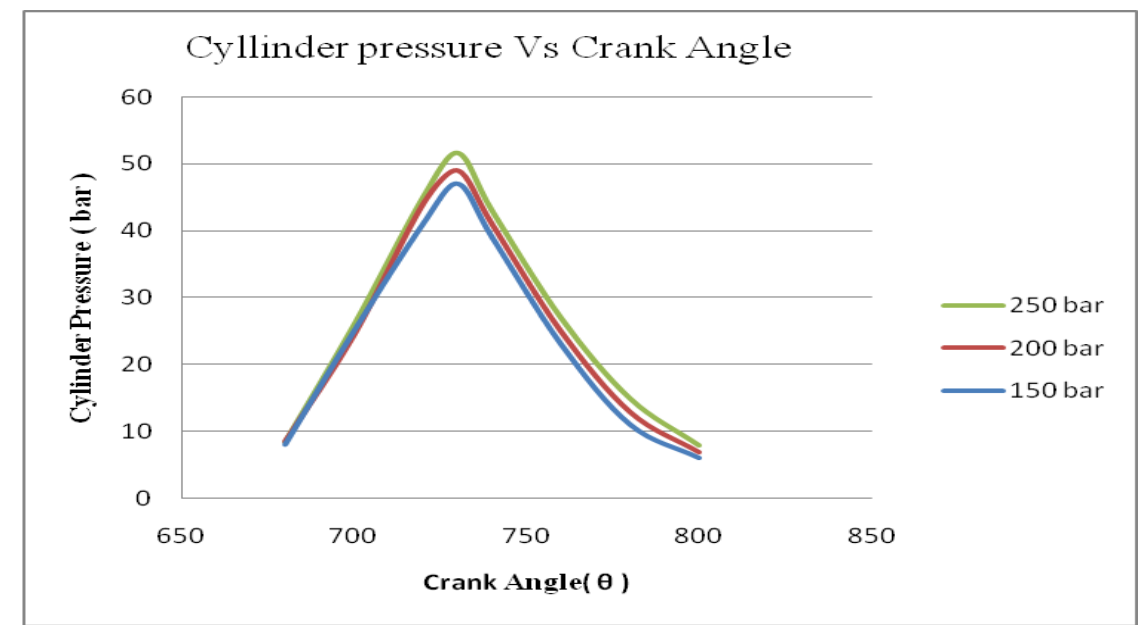

Fig.5. Cylinder pressure with respect to crank angle at various injection pressures

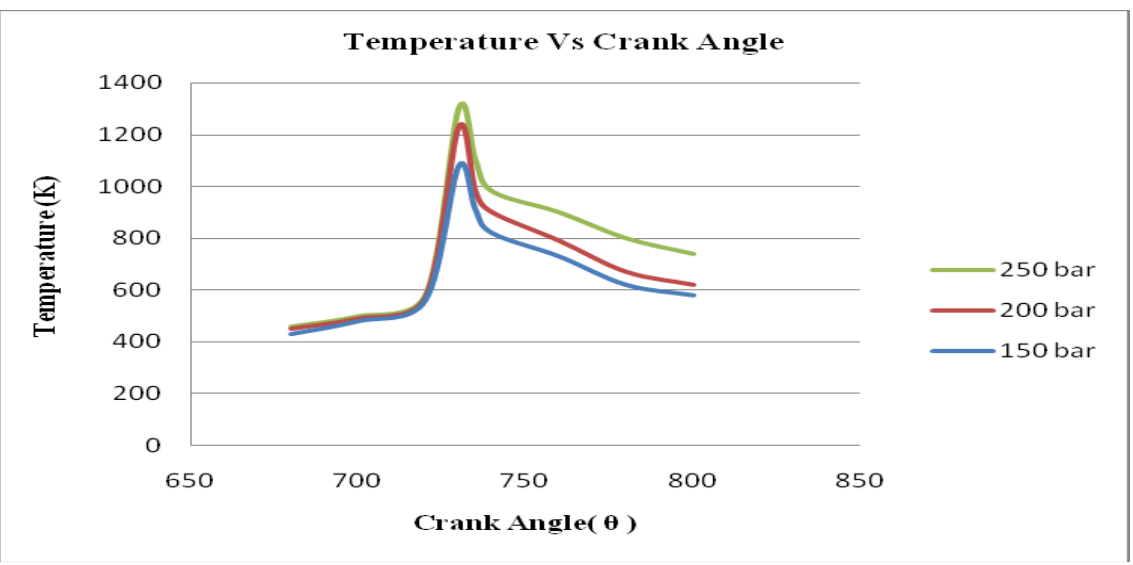

Fig.6. Cylinder Temperatures with respect to crank angle at various injection pressure

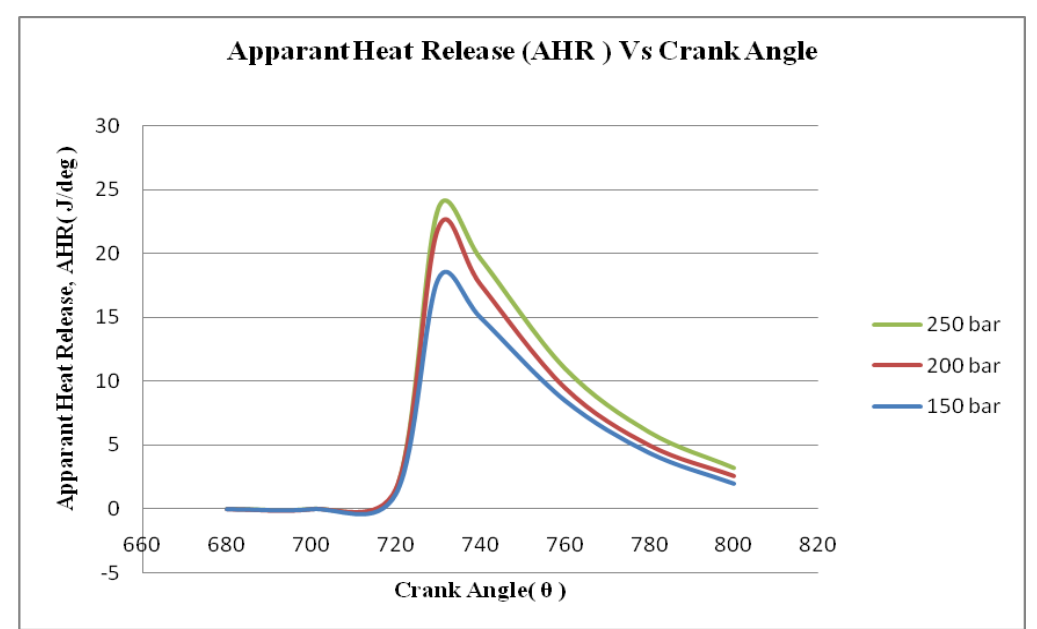

Fig 7. Apparent Heat Relase rate with respect to crank angle at various injection pressures

NOx and Soot formation also increases from $6.22 \mathrm{~g} / \mathrm{Kg}$ of fuel to $10.65 \mathrm{~g} / \mathrm{kg}$ of fuel and $0.17 \mathrm{~g} / \mathrm{kg}$ of fuel to $0.215 \mathrm{~g} / \mathrm{kg}$ of fuel. The variation of NOx and Soot with respect to crank angle at different Injection Pressure is shown in Fig 8and Fig 9. 


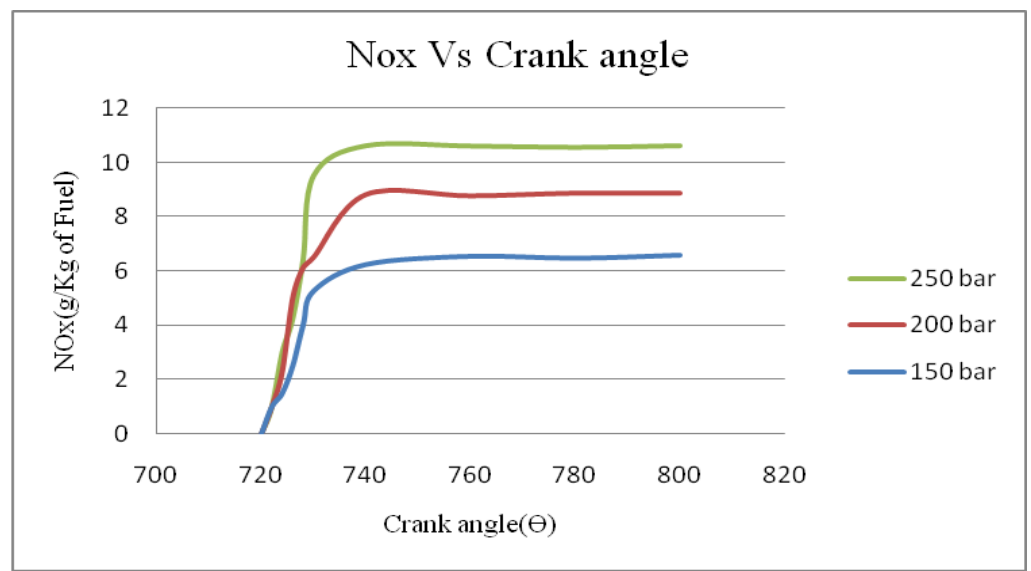

. Fig.8 The variation of NOx with respect to crank angle at different Injection Pressures

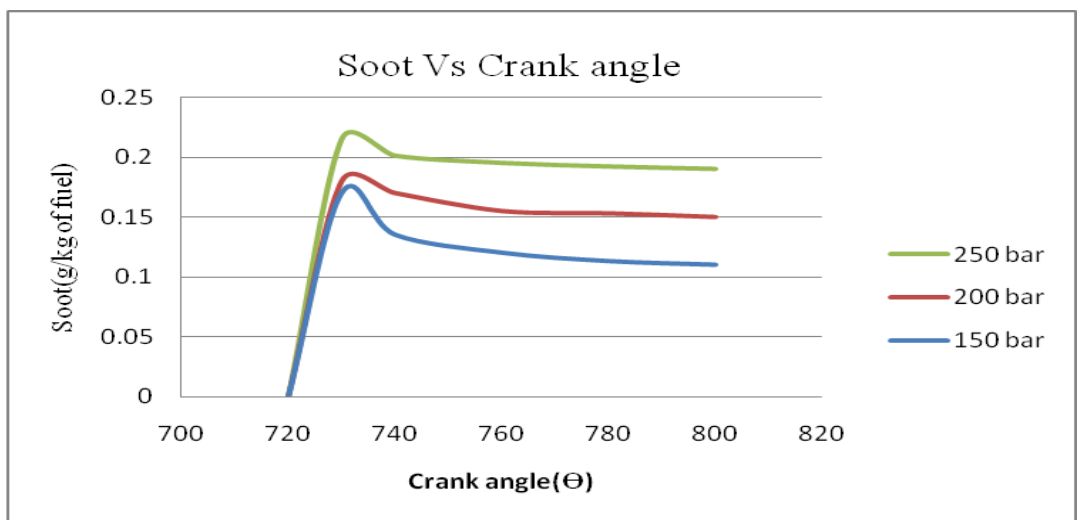

Fig.9 The variation of Soot with respect to crank angle at different Injection Pressures

\section{Conclusion}

In this present work, combustion parameters such as cylinder pressure, cylinder temperature, apparent heat release rate, NOx and Soot are studied at different injection pressures by CFD analysis. The following conclusions are obtained.

When the injection pressure increased from 150 bar to 250 bar the cylinder pressure increases by nearly 6 bar

$>$ The cylinder temperature increased by $16.9 \%$ when injection pressures increased from 150 bars to 250 bars

$>$ Apparent heat release rate increased by $23.5 \%$

$>$ NOx formation increased by $41.5 \%$ when injection pressure increases from 150 bar to 250 bars

$>$ Soot level increases by $20.9 \%$ as as injection pressure increased from 150 bar to 250 bars

\section{References}

[1]. K. Kannan and M. Udayakumar "Experimental Study of the Effect of Fuel Injection Pressure on Diesel Engine Performance and Emission" ARPN Journal of Mechanical and Engineering, e-ISSN: 1819-6608 Volume 5, VOL. 5, NO. 5, MAY 2010.

[2]. G. Suresh Babu, S. D. V. S. Jagadeesh, U.B. Sai charan, P.R.S .Praneeth, Analysis of a Single Cylinder Combustion Engine Using CFD, International Journal of Innovative Technology and Exploring Engineering (IJITEE), ISSN: 2278-3075, Volume-2, Issue-5, April 2013

[3]. Pathak Yogesh R1, Deore Kailas D2, Patil Vijayendra M3Shengli Wei, Feihu Wang, Xianyin Leng, Xin Liu, Kunpeng” Numerical analysis on the effect of swirl ratios on swirl chamber Combustion system of DI diesel engines" In Cylinder Cold Flow CFD Simulation of IC Engine using Hybrid Approach IJRET: International Journal of Research in Engineering and Technology, eISSN: 2319-1163 | pISSN: 2321-7308.

[4]. S Gavudhama karunanidhi, Manu Narayanan P M .G Subba Rao “CFD Studies of Split Injection on the Combustion and Emission Characteristics in DI Diesel Engine" S G Karunanidhi et al Int. Journal of Engineering Research and Applications . ISSN : 22489622, Vol. 4, Issue 7( Version 1), July 2014, pp.55-58

[5]. H. Sushma and Jagadeesha. K.B," CFD Modeling of the In-cylinder Flow in Direct-injection Diesel engine” International Journal of Scientific and Research Publications, Volume 3, Issue 12, December 2013 ISSN 2250-3153.

[6]. Darshana S. Gaikwad, Ajay V. Kolhe Experimental validation of combustion with CFD modeling in single cylinder four stroke CI engine fueled with biodiesel, Journal of Multidisciplinary Engineering Science and Technology (JMEST) ISSN: 3159-0040 Vol. 1 Issue 4, November - 2014. 